\title{
Cost-effectiveness analysis of HIV treatment in the clinical practice of a public hospital in northern Italy
}

This article was published in the following Dove Press journal:

Therapeutics and Clinical Risk Management

14 September 2012

Number of times this article has been viewed

\author{
Giuliano Rizzardini' \\ Paolo Bonfanti ${ }^{2}$ \\ Laura Carenzi' \\ Massimo Coen' \\ Giovanna Orlando' \\ Sergio Di Matteo ${ }^{3}$ \\ Giorgio L Colombo ${ }^{3,4}$ \\ 'Ist Infectious Diseases Department, \\ "L. Sacco" Hospital, Milan, Italy; \\ 2Infectious Diseases Department, \\ A Manzoni Hospital, Lecco, Italy; \\ ${ }^{3}$ S.A.V.E. Studi Analisi Valutazioni \\ Economiche, Milan, Italy; ${ }^{4}$ University \\ of Pavia, Department of Drug \\ Sciences, School of Pharmacy, Italy
}

Introduction: We carried out an economic analysis to assess the cost-effectiveness of highly active antiretroviral therapy (HAART) regimens in Italy for the management of human immunodeficiency virus (HIV)-infected patients according to clinical practice in the Infectious Diseases Department of "L. Sacco" Hospital, Milan, Italy.

Patients and methods: The incremental cost-effectiveness analysis was completed by means of a Markov model. Through a decision-analytic approach, this enabled us to compare the studied antiretroviral regimens. The model considered a population of adult HIV subjects who received HAART therapy for the first time according to clinical practice in the Infectious Diseases Department of "L. Sacco" Hospital, Milan. Data were investigated from the standpoint of the Lombardy Regional Health Service. We considered the following outcome measures: quality-adjusted life-years (QALYs), and direct health costs calculated for the years 2008 and 2009. The time horizon adopted in the model was 2 years.

Results: The model revealed that, in terms of cost per gained QALY, the tenofovir disoproxil fumarate + emtricitabine + efavirenz $(\mathrm{TDF}+\mathrm{FTC}+\mathrm{EFV})$ once-a-day treatment strategy seems to be the most cost-effective therapeutic choice $(€ 34,965)$; the incremental cost-effectiveness ratio (ICER) values for the remaining strategies ranged from $€ 53,000$ to around $€ 62,000$ per QALY. The validity of the base case scenario was then confirmed by means of a sensitivity analysis on the main variables.

Conclusion: The TDF+FTC+EFV treatment strategy (TDF/FTC+EFV fixed-dose combination then switched to single-tablet regimen [STR]) in this setting is the most cost-effective treatment strategy compared with the other therapeutic regimens. The ICER value for the TDF+FTC+EFV once-a-day then switched to STR treatment was lower than the internationally generally accepted threshold value of $€ 50,000$. The developed model is a tool for policy makers and health care professionals for creating short- and long-term cost projections, with the aim of assessing their impact on the available budgets for HIV patients.

Keywords: AIDS, HIV, HAART antiretroviral therapy regimens, single-tablet regimen (STR), Markov model, cost-effectiveness, quality-adjusted life-years, QALYs

\section{Introduction}

The economic burden of human immunodeficiency virus (HIV) infection is well recognized globally. ${ }^{1-3}$ The HIV prevalence and incidence data presented in the last report by the United Nations (UNAIDS) and World Health Organization (WHO) show that 33.3 million people in the world were HIV-infected in 2009, with 2.5 million new cases. ${ }^{1}$ Its management requires the use of health care services for treating HIV infection and symptoms associated with acquired immunodeficiency syndrome (AIDS) and with opportunistic infections, and involves indirect costs associated with
Correspondence: Giorgio L Colombo S.A.V.E. Studi Analisi Valutazioni Economiche, Via Previati,

74-20 I49, Milan, Italy

Tel +3902485 I 9230

Fax +390273960369

Email giorgio.colombo@unipv.it 
morbidity and premature death of working-age patients. Since the mid-1990s, highly active antiretroviral therapy (HAART) has modified the clinical course of HIV infection, reducing the rate of disease progression, the incidence of opportunistic infections, and mortality. ${ }^{4,5}$ Thanks to combination antiretroviral therapy, therefore, many HIV-infected patients now enjoy longer survival and a better quality of life. ${ }^{6,7}$

In Italy, the universal and public National Health Service (NHS) has delegated regions with the responsibility of organizing and administering publicly financed health care. The consequence has been the creation of different models around the country, both from an organizational and a funding point of view. Lombardy is the most populated of the 20 Italian regions, with 10 million inhabitants comprising over $15 \%$ of the Italian population in $2011 .^{8}$ Moreover, the Lombardy Region has the highest prevalence of AIDS cases in Italy, with a strong impact on the regional health care budget. According to data from the Italian Seroconversion Study, ${ }^{9,10}$ Lombardy has also one of the highest incidence rates in Italy (3.2 cases per 100,000 inhabitants). This inevitably has a great bearing on the regional health care system (the total expenditure for the care of HIV/AIDS patients, including the cost of care outside hospitals and residential homes, ie, in semiresidential housing, hospices, etc, now hovers around 300 million per year). ${ }^{11}$ In particular, the cost of antiretroviral therapy has gradually increased from about $€ 92$ million in 2004 to more than $€ 193$ in $2010 .{ }^{12}$ However, the need for regimens with powerful antiviral activity, proven long-term safety, good adherence, and a low rate of antiviral resistance should also be evaluated in terms of lifetime costs, since HIV is a long-lasting disease and its treatment may continue for many years. ${ }^{13}$ In a context of limited health care resources, pharmacoeconomic considerations are crucial to help policy makers make the most appropriate decisions on resource allocation. We therefore performed an economic analysis to assess the cost-effectiveness of the HAART regimens in the Lombardy Region for managing $\mathrm{HIV}$-infected patients according to clinical practice in the Infectious Diseases Department of "L. Sacco" Hospital, Milan, Italy.

\section{Methods}

\section{Structure of the model}

The study aimed to determine the incremental costeffectiveness ratio (ICER) per quality-adjusted life-years (QALYs) gained for HAART regimens of HIV-infected patients, according to clinical practice in the Infectious Diseases Department of “L. Sacco” Hospital, Milan.
We performed an incremental cost-effectiveness analysis by using and adapting a recently published Markov mode ${ }^{14}$ to case series of HIV-positive patients treated in the Infectious Diseases Department of “L. Sacco" Hospital, Milan during 2 years of observation. The Markov model simulates the quality of life and costs for an HIV patient, starting from the administration of the initial antiretroviral treatment and followed up in 1-year cycles. ${ }^{15}$ The model assigned patients responding to the antiretroviral therapy a viremia value lower than 50 copies and allowed responders to move within the CD4 classification. ${ }^{14}$ After entering the model and receiving one of the antiretroviral regimens, the patient can "move" through eight health states, defined by the CD4-cell count combined with the viremia levels (VL), one AIDS state, and one death state. The analysis was carried out from the point of view of the Lombardy Regional Health Service (RHS) in Italy. QALYs were considered as outcomes; the costs considered were direct health care costs, valuated for the year 2011. The model adopted a 2 -year time horizon. The studied antiretroviral regimens represent the pharmacological options used that had homogeneous characteristics during the period observed. The analyzed antiretroviral regimens represented the most frequently used pharmacological options during the study period. This economic evaluation considered QALYs as effectiveness indicators. The utility values, associated with the eight health states identified by the CD4-cell count, were calculated by Simpson et al. ${ }^{15-18}$

\section{Patients and transition probabilities}

The enrolled subjects are HIV patients who were referred to the HIV center at the First Infectious Diseases Department at the "L. Sacco" Hospital in Milan in the period between 2008 and 2009. The population included and evaluated in the model consists of subjects having similar and superimposable sociodemographic characteristics at the time of enrollment (2008). The patients' characteristics, which determined their selection in the group of pooled data, were divided into five macrogroups: demographics, comorbidities linked with hepatitis $\mathrm{C}$ virus (HCV) disease and comorbidities linked with hepatitis B virus (HBV) disease, treatment line, and adherence. The required data for these five large areas are reported in Table 1 . The analysis was carried out on four therapeutic combinations, which are summarized in Table 2.

The criteria for inclusion were as follows: age $\geq 18$ years, confirmed HIV infection, being resident in Lombardy, and being followed at the First Infectious Disease Department of "L. Sacco" Hospital in Milan during the observation 
Table I Patient characteristics at enrollment

\begin{tabular}{|c|c|c|c|c|c|c|c|c|c|c|c|c|c|c|c|}
\hline & \multicolumn{15}{|c|}{ Treatment regimens } \\
\hline & \multicolumn{2}{|c|}{$\begin{array}{l}\text { TDF FTC } \\
\text { EFV }\end{array}$} & \multicolumn{2}{|c|}{$\begin{array}{l}\text { TDF FTC } \\
\text { ATZ RTV }\end{array}$} & \multicolumn{2}{|c|}{$\begin{array}{l}\text { TDF FTC } \\
\text { LPV/r RTV }\end{array}$} & \multicolumn{2}{|c|}{$\begin{array}{l}\text { AZT 3TC } \\
\text { LPV/r RTV }\end{array}$} & \multicolumn{2}{|l|}{$M$} & \multicolumn{2}{|l|}{$\mathbf{F}$} & \multicolumn{2}{|c|}{ Total } & \\
\hline & $\mathbf{n}$ & (\%) & $\mathbf{n}$ & (\%) & $\mathbf{n}$ & (\%) & $\mathbf{n}$ & $(\%)$ & $\mathbf{n}$ & $(\%)$ & $\mathbf{n}$ & (\%) & $\mathbf{n}$ & (\%) & \\
\hline \multicolumn{16}{|l|}{ Age } \\
\hline$<30$ & 0 & 0.0 & 2 & 4.2 & 1 & 1.9 & 0 & 0.0 & 2 & 1.4 & 1 & 2.1 & 3 & 1.5 & \\
\hline $30-39$ & 22 & 37.9 & 11 & 22.9 & 18 & 34.0 & 10 & 28.6 & 45 & 30.6 & 16 & 34.0 & 61 & 31.4 & \\
\hline $40-49$ & 28 & 48.3 & 26 & 54.2 & 23 & 43.4 & 19 & 54.3 & 73 & 49.7 & 23 & 48.9 & 96 & 49.5 & \\
\hline $50-59$ & 5 & 8.6 & 4 & 8.3 & 8 & 15.1 & 4 & 11.4 & 19 & 12.9 & 2 & 4.3 & 21 & 10.8 & \\
\hline$\geq 60$ & 3 & 5.2 & 5 & 10.4 & 3 & 5.7 & 2 & 5.7 & 8 & 5.4 & 5 & 10.6 & 13 & 6.7 & 194 \\
\hline \multicolumn{16}{|l|}{ HCV infections? } \\
\hline Pos & 16 & 27.6 & 21 & 43.8 & 15 & 28.3 & 10 & 28.6 & 47 & 32.0 & 15 & 31.9 & 62 & 32.0 & \\
\hline Neg & 37 & 63.8 & 24 & 50.0 & 34 & 64.2 & 23 & 65.7 & 89 & 60.5 & 29 & 61.7 & 118 & 60.8 & \\
\hline Unknown & 5 & 8.6 & 3 & 6.3 & 4 & 7.5 & 2 & 5.7 & II & 7.5 & 3 & 6.4 & 14 & 7.2 & 194 \\
\hline HCV RNA detectable? & 58 & & 48 & & 53 & & 35 & & & & & & & & \\
\hline $\mathrm{HCV}$ negative & 37 & 63.8 & 24 & 50.0 & 34 & 64.2 & 23 & 65.7 & 89 & 60.5 & 29 & 61.7 & 118 & 60.8 & \\
\hline Y & 8 & 13.8 & 14 & 29.2 & 8 & 15.1 & 6 & 17.1 & 27 & 18.4 & 9 & 19.1 & 36 & 18.6 & \\
\hline $\mathrm{N}$ & 4 & 6.9 & 4 & 8.3 & 6 & 11.3 & 4 & 11.4 & 14 & 9.5 & 4 & 8.5 & 18 & 9.3 & \\
\hline ND & 9 & 15.5 & 6 & 12.5 & 5 & 9.4 & 2 & 5.7 & 17 & 11.6 & 5 & 10.6 & 22 & 11.3 & 194 \\
\hline \multicolumn{16}{|l|}{ Treated for HCV } \\
\hline \multicolumn{16}{|l|}{ in $2008 / 09 ?$} \\
\hline $\mathrm{HCV}$ negative & 37 & 63.8 & 24 & 50.0 & 34 & 64.2 & 23 & 65.7 & 89 & 60.5 & 29 & 61.7 & 118 & 60.8 & \\
\hline$Y$ & 3 & 5.2 & 3 & 6.3 & 3 & 5.7 & 0 & 0.0 & 6 & 4.1 & 3 & 6.4 & 9 & 4.6 & \\
\hline $\mathrm{N}$ & 10 & 17.2 & 14 & 29.2 & 10 & 18.9 & 10 & 28.6 & 34 & 23.1 & 10 & 21.3 & 44 & 22.7 & \\
\hline Unknown & 8 & 13.8 & 7 & 14.6 & 6 & 11.3 & 2 & 5.7 & 18 & 12.2 & 5 & 10.6 & 23 & 11.9 & 194 \\
\hline \multicolumn{16}{|l|}{ HBsAg? } \\
\hline Pos & 2 & 3.4 & 5 & 10.4 & 5 & 9.4 & I & 2.9 & 11 & 7.5 & 2 & 4.3 & 13 & 6.7 & \\
\hline $\mathrm{Neg}$ & 51 & 87.9 & 38 & 79.2 & 44 & 83.0 & 32 & 91.4 & 125 & 85.0 & 40 & 85.1 & 165 & 85.1 & \\
\hline Unknown & 5 & 8.6 & 5 & 10.4 & 4 & 7.5 & 2 & 5.7 & 11 & 7.5 & 5 & 10.6 & 16 & 8.2 & 194 \\
\hline \multicolumn{16}{|l|}{ Naive in early 2008? } \\
\hline Y & 5 & 8.6 & 5 & 10.4 & 5 & 9.4 & 4 & 11.4 & 14 & 9.5 & 5 & 10.6 & 19 & 9.8 & \\
\hline $\mathrm{N}$ & 53 & 91.4 & 43 & 89.6 & 48 & 90.6 & 31 & 88.6 & 133 & 90.5 & 42 & 89.4 & 175 & 90.2 & 194 \\
\hline \multicolumn{16}{|l|}{$\begin{array}{l}\text { If naive, treatment } \\
\text { started in } 2008 / 09 ?\end{array}$} \\
\hline $\mathrm{N}$ & 53 & 91.4 & 43 & 89.6 & 48 & 90.6 & 31 & 88.6 & 133 & 90.5 & 42 & 89.4 & 175 & 90.2 & \\
\hline Y & 5 & 8.6 & 5 & 10.4 & 5 & 9.4 & 4 & 11.4 & 14 & 9.5 & 5 & 10.6 & 19 & 9.8 & 194 \\
\hline \multicolumn{16}{|l|}{ Is patient in first line? } \\
\hline Y & 19 & 32.8 & 8 & 16.7 & 16 & 30.2 & II & 31.4 & 46 & 31.3 & 8 & 17.0 & 54 & 27.8 & \\
\hline $\mathrm{N}$ & 38 & 65.5 & 37 & 77.1 & 37 & 69.8 & 24 & 68.6 & 97 & 66.0 & 39 & 83.0 & 136 & 70.1 & \\
\hline ND & 1 & 1.7 & 3 & 6.3 & 0 & 0.0 & 0 & 0.0 & 4 & 2.7 & 0 & 0.0 & 4 & 2.1 & 194 \\
\hline \multicolumn{16}{|l|}{ Adherence } \\
\hline Missing data & 2 & 3.4 & 0 & 0.0 & 4 & 7.5 & 2 & 5.7 & 3 & 2.0 & 5 & 10.6 & 8 & 4.1 & \\
\hline Y & 56 & 96.6 & 44 & 91.7 & 43 & 81.1 & 32 & 91.4 & 137 & 93.2 & 38 & 80.9 & 175 & 90.2 & \\
\hline $\mathrm{N}$ & 0 & 0.0 & 4 & 8.3 & 6 & 11.3 & 1 & 2.9 & 7 & 4.8 & 4 & 8.5 & 11 & 5.7 & 194 \\
\hline \multicolumn{16}{|l|}{ Treatment change } \\
\hline in $2008 / 2009 ?$ & & & & & & & & & & & & & & & \\
\hline Y & 8 & 13.8 & 11 & 22.9 & 18 & 34.0 & 13 & 37.1 & 32 & 21.8 & 18 & 38.3 & 50 & 25.8 & \\
\hline $\mathrm{N}$ & 50 & 86.2 & 37 & 77.1 & 35 & 66.0 & 22 & 62.9 & 115 & 78.2 & 29 & 61.7 & 144 & 74.2 & 194 \\
\hline
\end{tabular}

Abbreviations: TDF, tenofovir; FTC, emtricitabine; EFV, efavirenz; ATZ, atazanavir; RTV, ritonavir; LPV/r, ritonavir-boosted lopinavir; AZT, zidovudine; 3TC, lamivudine; $\mathrm{HCV}$, hepatitis $\mathrm{C}$ virus; $\mathrm{HBsAg}$, hepatitis $B$ surface antigen; HCV RNA, hepatitis $C$ virus ribonucleic acid.

period (2008-2009), with at least one laboratory test (CD4 cell count and/or VL) per year during the study period. ${ }^{13}$ Patients were excluded in case of missing clinical data (subjects not referring to the center for more than 12 months) or cost information (patients not resident in Lombardy). The personal details for each patient (sex, age, ethnicity, risk factor for HIV acquisition) were recorded, as well as clinical information (highest VL and lowest CD4+ cell count in each year, antiretroviral treatment [ART] history, HCV and HBV coinfection). These data were collected from the medical records of the First Infectious Diseases Department of the "L. Sacco" Hospital. During the first visit at the HIV center, 
Table 2 Patient distribution per treatment, based on CD4-cell count and viremia

\begin{tabular}{|c|c|c|c|c|c|c|c|c|c|}
\hline \multirow{2}{*}{$\begin{array}{l}\text { CD4 viremia } \\
\text { treatment }\end{array}$} & \multicolumn{2}{|c|}{$>500$ cells $/ \mu \mathrm{L}$} & \multicolumn{2}{|c|}{$35 \mathrm{I}-500 \mathrm{cells} / \mu \mathrm{L}$} & \multicolumn{2}{|c|}{$20 \mathrm{I}-350 \mathrm{cells} / \mu \mathrm{L}$} & \multicolumn{2}{|c|}{$<200$ cellule/ $\mu \mathrm{L}$} & \multirow{2}{*}{$\begin{array}{l}\text { Total patients } \\
\text { treated }\end{array}$} \\
\hline & $<\mathbf{5 0}$ & $\geq \mathbf{5 0}$ & $<\mathbf{5 0}$ & $\geq \mathbf{5 0}$ & $<\mathbf{5 0}$ & $\geq \mathbf{5 0}$ & $<\mathbf{5 0}$ & $\geq \mathbf{5 0}$ & \\
\hline TDF FTC EFV & 23 & 4 & II & I & 7 & 4 & 5 & 3 & 58 \\
\hline TDF FTC ATZ RTV & 16 & 6 & II & 3 & 3 & 2 & 4 & 3 & 48 \\
\hline TDF FTC LPV/r RTV & 18 & 4 & 9 & 3 & 8 & 4 & 4 & 3 & 53 \\
\hline AZT 3TC LPV/r RTV & II & 4 & 5 & 4 & 3 & 4 & I & 3 & 35 \\
\hline Total & 68 & 18 & 36 & II & 21 & 14 & 14 & 12 & 194 \\
\hline
\end{tabular}

Abbreviations: TDF, tenofovir; FTC, emtricitabine; EFV, efavirenz; ATZ, atazanavir; RTV, ritonavir; LPV/r, ritonavir-boosted lopinavir; AZT, zidovudine; 3TC, lamivudine.

patients signed a one-time general informed consent to the use of their data. All data were anonymously processed and analyzed. ${ }^{13}$ Tables 1 and 2 show the characteristics of patients considered in the model, with respect to the CD4 cell count. Data were gathered at 6-month intervals during the 2 years, with four total data collection intervals. Atripla ${ }^{\circledR}$ (Gilead Sciences Inc, Foster City, CA) became available in the hospital in July 2008. So all patients taking tenofovir disoproxil fumarate + emtricitabine + efavirenz $(\mathrm{TDF}+\mathrm{FTC}+\mathrm{EFV})$ once a day until that moment used a fixed-dose combination of $\mathrm{TDF}+\mathrm{FTC}$ and EFV, and then switched to a single-tablet regimen (STR).

\section{Resource consumption and costs}

The perspective assumed was the Lombardy RHS. The consumption of resources for the patients considered in the model is associated with the administration of the antiretroviral regimens and with other direct health care costs, such as hospitalizations, medical examinations, laboratory tests, and so on. We were able to perform a patient-based analysis, because we collected cost data from the Integrated Patients' Database (Banca Dati Assistito) of the Lombardy Region. This data warehouse contains three main databases (outpatient activity, pharmaceuticals, and inpatient activity) recording all health care services provided to each patient by any (public or accredited private) hospital or clinic in the RHS. ${ }^{13}$ The RHS provides reimbursement for outpatient activities (medical examinations, laboratory and diagnostic procedures), hospital admissions, HAART, and non-HAART drugs to each regional health care structure. The data collected are therefore the real costs incurred by the RHS, ie, the bills paid to the (both public and private) providers for services delivered to each patient. Data on non-HAART drugs include all drugs prescribed to a patient and collected at any provider within the Lombardy Region, such as hospitals and pharmacies. These data were collected for the study period and anonymously linked to the clinical and personal data through a univocal code. All economic data collected referred to the year in which they were incurred. Costs were then discounted at the 2011 level, based on the Italian inflation rates of average consumer prices. In the cost analyses, the evolution of both total cost and of each cost category between 2008 and 2009 was considered. All clinical data were then analyzed to identify patient characteristics which may be related to the costs in each year, taking into account CD4 cell count $(<200,200-350,351-499$, $\geq 500$ cells $/ \mathrm{mm}^{3}$ ).

Information on the consumption of resources such as hospitalizations, outpatient care, general practitioner and specialist examinations, laboratory tests, and diagnostic procedures expressed as $\mathrm{CD} 4$ cell count in patients involved in the survey is shown in Table 3, whereas Table 4 shows the average annual costs for each first-line regimen used at the "L. Sacco" Hospital, based on the reimbursement price paid by the RHS, which takes into account the price updates effective from January 1, 2011. ${ }^{19,20}$

The Mann-Whitney or Kruskal-Wallis tests were used to compare cost data, for two-group and three-or-more

Table 3 Average annual cost per patient and health state expressed in CD4 (excluding HAART cost)

\begin{tabular}{|c|c|c|c|c|c|c|c|c|}
\hline \multirow{2}{*}{$\begin{array}{l}\text { CD4 viraemia } \\
\text { Other costs }\end{array}$} & \multicolumn{2}{|c|}{$>500$ cellule $/ \mu \mathrm{L}$} & \multicolumn{2}{|c|}{$35 \mathrm{I}-500$ cellule/ $\mu \mathrm{L}$} & \multicolumn{2}{|c|}{$20 \mathrm{I}-350$ cellule/ $\mu \mathrm{L}$} & \multicolumn{2}{|c|}{$<200$ cellule/ $\mu \mathrm{L}$} \\
\hline & $<\mathbf{5 0}$ & $\geq \mathbf{5 0}$ & $<\mathbf{5 0}$ & $\geq \mathbf{5 0}$ & $<\mathbf{5 0}$ & $\geq \mathbf{5 0}$ & $<\mathbf{5 0}$ & $\geq \mathbf{5 0}$ \\
\hline Healthcare services & $€ 1349$ & $€ \mid 490$ & $€ \mid 459$ & $€ 1619$ & $€ 1610$ & $€ 1794$ & $€ 1700$ & $€ I 675$ \\
\hline Other drugs & $€ 325$ & $€ 254$ & $€ 366$ & $€ 377$ & $€ 510$ & $€ 266$ & $€ 840$ & $€ 648$ \\
\hline Hospitalizations & $€ 610$ & $€ 975$ & $€ 1509$ & $€ \mid 488$ & $€ 719$ & $€ 2733$ & $€ 2798$ & $€ 5025$ \\
\hline Total & $€ 2284$ & $€ 2719$ & $€ 3333$ & $€ 3484$ & $€ 2839$ & $€ 4793$ & $€ 5337$ & $€ 7348$ \\
\hline
\end{tabular}

Note: Data on file: “L. Sacco" Hospital, Milan; Integrated Patients' Database (Banca Dati Assistito) of the Lombardy Region; 2012.

Abbreviation: HAART, highly active antiretroviral therapy. 
Table 4 Average annual costs for each first-line therapeutic HAART regimen

\begin{tabular}{ll}
\hline Treatment & Annual costs HAART treatment \\
\hline TDF FTC EFV & $€ 7226$ \\
TDF FTC ATZ RTV & $€ 9016$ \\
TDF FTC LPV/r RTV & $€ 9018$ \\
AZT 3TC LPV/r RTV & $€ 7642$ \\
\hline
\end{tabular}

Note: Data on file: “L. Sacco" Hospital, Milan - Prices 20II; 2012.

Abbreviations: HAART, highly active antiretroviral therapy; TDF, tenofovir; FTC, emtricitabine; EFV, efavirenz; ATZ, atazanavir; RTV, ritonavir; LPV/r, ritonavirboosted lopinavir; AZT, zidovudine; 3TC, lamivudine.

group comparisons, respectively. In order to include all significant variables affecting the costs of care in the univariate analysis, we applied a generalized linear model with a $\log$ link and a gamma distribution, as recommended for heavily skewed or tailed data. SAS for Windows software (v. 9.1; SAS Institute Inc, Cary, NC) was employed to perform all analyses.

\section{Cost-effectiveness analysis}

The ICER was utilized to assess cost-effectiveness. In the assessment of the value of a therapeutic option, the ICER provides the additional resources needed to achieve the additional benefit (QALYs). The ICER is the difference in cost $(\Delta \mathrm{C})$ divided by the difference in effect $(\Delta \mathrm{E})$ between two alternatives. This analysis compared the direct costs and effectiveness of each drug with the direct costs and effectiveness of the disease natural history (absence of treatment). The cost and QALYs of the disease natural history were taken from the model in Colombo et $\mathrm{al}^{14}$ based on literature and epidemiologic data.

\section{Sensitivity analysis}

The sensitivity analysis verified the impact of a series of variations of the base case having a large influence on the obtained results. Some parameters of the simulation model were subjected to a series of univariate analyses, taking into account ${ }^{21}$ Italian guidelines, the variation $( \pm 20 \%)$ of the HAART cost, the variation ( $\pm 20 \%$ ) of other costs associated with the HIV patient and, lastly, the variation $( \pm 5 \%)$ of the utility parameter.

\section{Results}

Table 5 shows the average annual cost and the QALYs for a patient with HIV treated with each of the first-line antiretroviral regimens used in the First Infectious Diseases Department of "L. Sacco" Hospital, Milan. The simulation model shows that patients treated with a once-daily TDF+FTC+EFV treatment strategy (0.982 QALYs/year) have a better quality of life, with a higher number of QALYs than with other therapeutic regimens. Table 5 also shows the annual average cost of treatment (therapeutic regimens + other medical costs) for a patient with HIV. TDF+FTC+EFV has a lower mean treatment cost $(€ 10,140)$. The comparison of the above-mentioned costs and outcomes in incremental terms (ICER) with the no-treatment strategy showed that the $\mathrm{TDF}+\mathrm{FTC}+\mathrm{EFV}$ once-daily treatment strategy is the most cost-effective therapeutic choice $(€ 34,965)$; the ICER values for the remaining strategies range from $€ 53,000$ to about $€ 62,000$ per QALY.

The sensitivity analysis of the main variables does not highlight significant variations with respect to the analyzed base case (Figure 1).

\section{Discussion}

Since 1996, owing to the discovery of new classes of drugs and molecules capable of hindering viral replication on various fronts, and especially with the introduction of combined therapies, the life expectancy and quality of life of people with HIV have enormously improved. The addition of new antiretroviral regimens to conventional therapies can help clinicians in the choice of the best possible treatment for HIV patients. ${ }^{22}$ We therefore performed an incremental costeffectiveness analysis for each treatment regimen for HIV patients, from the RHS standpoint. A recently published model was used for this analysis. The input data were the clinical evolution of consecutively enrolled patients at the

Table 5 Costs, QALYs, and incremental cost-effectiveness ratio of the base case scenario

\begin{tabular}{|c|c|c|c|c|c|c|}
\hline Treatment & $\begin{array}{l}\text { Mean cost } \\
\text { per patient }\end{array}$ & $\begin{array}{l}\text { Mean QALYs } \\
\text { per patient }\end{array}$ & $\begin{array}{l}\text { Mean cost } \\
\text { per QALYs }\end{array}$ & $\begin{array}{l}\text { Delta } \\
\text { cost }\end{array}$ & $\begin{array}{l}\text { Delta } \\
\text { QALYs }\end{array}$ & $\begin{array}{l}\text { ICER } \\
\text { QALYs }\end{array}$ \\
\hline Untreated & $€ 3431$ & 0.790 & & & & \\
\hline TDF FTC EFV & $€ 10,140$ & 0.982 & $€ 10,327$ & $€ 6709$ & 0.192 & $€ 34,965$ \\
\hline TDF FTC ATZ RTV & $€|2| 0 \mid$, & 0.930 & $€ \mid 3,008$ & $€ 8670$ & 0.140 & $€ 61,812$ \\
\hline TDF FTC LPV/r RTV & $€ 12,026$ & 0.932 & $€ \mid 2,900$ & $€ 8595$ & 0.142 & $€ 60,423$ \\
\hline AZT 3TC LPV/r RTV & $€ 10,927$ & 0.931 & $€|I, 73|$ & $€ 7496$ & 0.141 & $€ 53,008$ \\
\hline
\end{tabular}

Abbreviations: QALYs, quality-adjusted life-years; ICER, incremental cost-effectiveness ratio; TDF, tenofovir; FTC, emtricitabine; EFV, efavirenz; ATZ, atazanavir; RTV, ritonavir; LPV/r, ritonavir-boosted lopinavir; AZT, zidovudine; 3TC, lamivudine. 


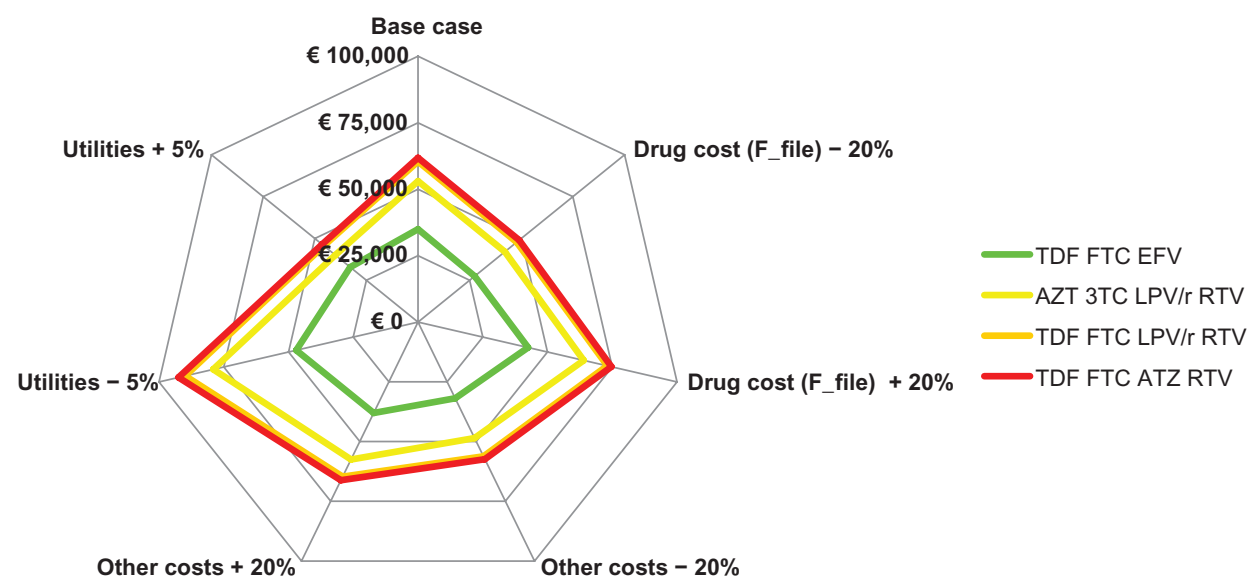

Figure I Results of one-way sensitivity analyses: ICER per QALYs in different scenarios.

Abbreviations: QALYs, quality-adjusted life-years; ICER, incremental cost-effectiveness ratio; TDF, tenofovir; FTC, emtricitabine; EFV, efavirenz; ATZ, atazanavir; RTV, ritonavir; LPV/r, ritonavir-boosted lopinavir; AZT, zidovudine; 3TC, lamivudine.

First Infectious Diseases Department of "L. Sacco" Hospital, Milan, during 2008-2009, for whom the annual health care data were known. Thus it was possible to observe and simulate the cost per QALY of the different treatment regimens adopted in clinical practice within a 2 -year time horizon, and to develop some considerations on the various treatments for the treated patients in terms of cost per QALY.

The TDF+FTC+EFV once-daily regimen, with a cost per QALY of $€ 34,965$, was shown to be the most cost-effective treatment strategy by the results of the model, based on the clinical practice of a hospital center of reference, in the comparison with the other therapeutic regimens. This regimen is the only one of the four analyzed therapeutic regimens having a lower cost per QALY than the threshold value of $€ 50,000$, commonly accepted at an international level. ${ }^{23}$ This value expresses the willingness of the decision makers to spend in order to obtain additional health units, or to make new therapies available to citizens. Though no officially established threshold is available for Italy, it is worth noting that recent guidelines by the Italian Health Economics Association ${ }^{21}$ recommend the adoption of a threshold of $€ 25,000-40,000$. Other acceptable cost-effectiveness references for the Italian context are $€ 36,500$ and $€ 60,000$, as calculated by two different authors. ${ }^{24,25}$ The favorable result of the TDF+FTC+EFV once-daily treatment strategy is probably due to a better patients' adherence (see Table 1), which determines an increase in the quality of life of patients with HIV. ${ }^{26}$ However, low adherence to antiretroviral drugs is now recognized to be strictly linked with therapeutic regimen failure $^{27}$ and, consequently, with the indicators of the HIVdisease progression, such as virological failure, ${ }^{28}$ insufficient immunologic reconstitution, the clinical progression of the disease and, lastly, death. ${ }^{29-31}$
The sensitivity analysis of the main variables confirmed the validity of the base case. It is interesting to note the differences between this model, built on the base of real practice data, and the recently published model built on the base of literature data, ${ }^{32}$ also regarding Italy. The development methods and the QALYs are identical in both simulations, whereas there is a difference in the evolution data for patients in the various levels of CD4, in costs and in the used time horizon ( 2 years vs 10 years in the literature model used as benchmark). Table 5 indicates that, in our clinical practice simulation, the cost per QALY is $18 \%$ higher than the literature model on average although still with differences favorable to TDF+FTC+EFV. Such differences in literature data can be due to the presence of coinfections (which increases the total annual cost of treatment), and to the lower duration of the simulation interval (2 years of this analysis vs 10 years or lifetime). These differences also need to be integrated with some clinical considerations regarding the group of observed patients. First of all, our model only considers $9.8 \%$ of patients to be naïve in early 2008 , in comparison to the hypothetical cohort of $100 \%$ of naïve patients included in the simulation based on literature data. ${ }^{32}$ Also, Atripla (STR) became available in the hospital in July 2008. So all patients taking TDF+FTC+EFV once a day until that moment used a fixed-dose combination of TDF+FTC and EFV, and then switched to STR. Moreover, the majority of groups followed in the clinical practice had a previous longer disease duration, which certainly had an impact on the result expressed in terms of costs saved per year of life. With the analysis of naïve patients only, under the same terms used in our analysis, and within a 10-year time horizon, the results of the two research studies would certainly converge. 
There are a few limitations to the study, the most important of which concerns the quality of data entered into model: for example, parameters such as efficacy are based on data analysis in a limited time frame ( 2 years) and may therefore be inadequate for modeling the treatment of a chronic disease for a longer time. Another critical limitation concerns the utilities, which were derived from different literature sources and considered to be acceptable for an Italian population. Furthermore, as mentioned previously, the presence of a limited number of naive patients might have influenced the rate of response of patients to the treatments. In conclusion, it is worth observing that the developed model is a dynamic instrument that can be adapted to various health care settings (overall in chronic diseases such as HBV or HIV), since it can be run using different input data (ie, efficacy, costs, and epidemiological data)..$^{32}$ Mathematical models can assist policy makers in comparing the relative impact and costeffectiveness of different regimes, generalizing the results of randomized controlled trials to the local setting, identifying threats to program success, identifying opportunities for maximizing intervention impact/efficiency, and evaluating the extent to which observed trends in HIV prevalence are attributable to HIV/AIDS program success. ${ }^{33}$ Because it allows simulations of different scenarios, the model is an invaluable tool for policy makers and health care professionals to make short- and long-term cost projections and thus assess their impact on the available budgets.

\section{Acknowledgments}

We thank Davide Croce and the Libera Università Carlo Cattaneo (LIUC) staff for their contribution in providing health states costs data and Elena Ricci (PhD) First Infectious Diseases Department of "L. Sacco" Hospital, Milan. Cost data was evaluated by data warehouse L. Sacco.

\section{Disclosure}

This research was supported by Gilead Sciences Srl, Milan, Italy. The authors are employees of independent research organizations and maintained independent scientific control over the study, including data analysis and interpretation of final results.

\section{References}

1. World Health Organisation. Global Summary of the HIV/AIDS Epidemic. Geneva, Switzerland: World Health Organization; 2009.

2. Steinbrook R. Providing antiretroviral therapy for HIV infection. N Engl J Med. 2001;344:844-846.

3. Schackman BR, Gebo KA, Walensky RP, et al. The lifetime cost of current human immunodeficiency virus care in the United States. Med Care. 2006;44:990-997.
4. Mocroft A, Ledergerber B, Katlama C, et al; EUROSIDA study group. Decline in the AIDS and Death rates in the EUROSIDA study: an observational study. Lancet. 2003;362:22-29.

5. The Antiretroviral Therapy Cohort Collaboration. Life expectancy of individuals on combination antiretroviral therapy in high-income countries: a collaborative analysis of 14 cohort studies. Lancet. 2008;372:293-299.

6. Freedberg KA, Losina E, Weinstein MC, et al. The cost effectiveness of combination antiretroviral therapy for HIV disease. $N$ Engl $J$ Med. 2001;344:824-831.

7. Volberding PA, Deeks SG. Antiretroviral therapy and management of HIV infection. Lancet. 2010;376:49-62.

8. Demography in figures [webpage on the Internet]. Demographic statistics. Rome: Istituto Nazionale di Statistica; 1999, 2008. Available from: http://www.demo.istat.it/index_e.html. Accessed July 10, 2011.

9. Istituto Superiore di Sanità [Institute of Health]. Notiziario dell'Istituto Superiore di Sanità 2010. 2010;23(4Suppl1). Available from: http:// www.iss.it $/$ publ $/$ noti/cont.php?id $=2449 \&$ lang $=1 \&$ tipo $=4 \&$ anno $=201$ 0 . Accessed June 10, 2012. Italian.

10. Istituto Superiore di Sanità [Institute of Health]. Aggiornamento delle nuove diagnosi di infezione da HIV e dei casi di AIDS in Italia [Update of new diagnoses of HIV infection and AIDS cases in Italy]. Available from: http://www.iss.it/binary/pres/cont/dic2008.1228391047.pdf. Accessed November 13, 2011. Italian.

11. Lombardy Region. The Social and Healthcare Plan, No 937/2010. Available from: http://www.sanita.regione.lombardia.it/cs/Satellite?c $=$ Redazionale_P\&childpagename=DG_Sanita\%2FDetail\&cid $=1213$ 398553292\&packedargs $=$ NoSlotForSitePlan\%3Dtrue $\% 26$ menu-to-re nder\%3D1213277443740\&pagename=DG_SANWrapper. Accessed June 10, 2012. Italian.

12. Lombardy Region. Decree n. 748505 August 2011. Approvazione del documento avente peroggetto Percorso Diagnostico Terapeutico (PDT) per il paziente affetto da malattia HIV/AIDS [Therapeutic and Diagnostic Path (PDT) for the patient with HIV disease]. Available from: http:// www.sanita.regione.lombardia.it/cs/Satellite?c=Page\&childpagename $=$ DG_Sanita/Page/NormativaDetail\&pagename $=$ DG_SANWrapper\& cid $=1213275902673 \&$ keyid=3520. Accessed June 10, 2012. Italian.

13. Rizzardini G, Restelli U, Bonfanti P, et al. The cost of HIV disease in Northern Italy: the payer's perspective. J Acquir Immune Defic Syndr. 2011;57:211-217.

14. Colombo GL, Colangeli V, Di Biagio A, Di Matteo S, Viscoli C, Viale P. Cost-effectiveness analysis of initial HIV treatment under Italian guidelines. Clinicoecon Outcomes Res. 2011;3:197-205.

15. Simpson KN, Strassburger A, Jones WJ, Dietz B, Rajagopalan R. Comparison of Markov model and discrete-event simulation techniques for HIV. Pharmacoeconomics. 2009;27:159-165.

16. Simpson KN, Luo MP, Chumney E, et al. Cost-effectiveness of lopinavir/ ritonavir versus nelfinavir as the first-line highly active antiretroviral therapy regimen for HIV irtfection. HIV Clin Trials. 2004;5:294-304.

17. EuroQol Group. EQ-5D. Available from: http://www.euroqol.org. Accessed February 20, 2011.

18. Ravasio R. Analisi di costo-efficacia di entrcitabina/tenofovir disoproxil più efavirenz rispetto ad altri regimi antiretrovirali nel trattamento di prima linea di pazienti affetti da HIV [Cost-effectiveness analysis of emtricitabine/tenofovir disoproxil plus efavirenz versus other antiretroviral regimes in first line treatment of HIV patients]. Giornale Italiano di Health Technology Assessement. 2010;3(1):1-11. Italian.

19. AIFA Italian Drug Agency. Negoziazione e rimborsabilitá [Negotiation and reimbursement]. Available from: http://www.agenziafarmaco.govit/it/content negoziazione-e-rimborsabilit\%C3\%A0. Accessed November 13, 2011. Italian.

20. TimeSeries Italian Historical Statistical Repository [webpage on the Internet]. Rome: Istituto Nazionale di Statistica; nd. Available from: http://timeseries.istat.it. Accessed November 10, 2011.

21. AIES Italian Health Economics Association. Associazione Italiana di Economia Sanitaria. Italian Guidelines proposal on how to conduct economic evaluation studies of health programs. Pharmacoeconomics Italian Research Articles. 2009;11:83-93. 
22. Regione Emilia-Romagna. Lo stato dell'infezione da HIV/AIDS in emiliaromagna Aggiornamento sull'epidemia e primi risultati del sistema di sorveglianza dell'infezione da HIV al 31/12/2009 [Epidemiologic survey on HIV/AIDS, 31/12/2009]. Available from: http:// www.helpaids.it/flex/cm/pages/ServeBLOB.php/L/IT/IDPagina/50. Accessed November 10, 2011. Italian.

23. Jonsson B. Changing health environment: the challenge to demonstrate cost-effectiveness of new compounds. Pharmacoeconomics. 2004;22(Suppl 4):5-10.

24. Lucioni C, Ravasio R. Come valutare i risultati di uno studio farmacoeconomico? [How to evaluate the results of a pharmacoeconomic study?] PharmacoEconomics - Italian Research Articles. 2004; 3:121-130. Italian.

25. Messori A, Santarlasci B, Trippoli S, Vaiani M. Controvalore economico del farmaco e beneficio clinico: Stato dell'arte della metodologia e applicazione di un algoritmo farmacoeconomico [Clinical benefit and economic value: methodology and an economic application]. Pharmaco Economics - Italian Research Articles. 2003;5:53-67. Italian.

26. Airoldi M, Zaccarelli M, Bisi L, et al. One-pill once-a-day HAART: a simplification strategy that improves adherence and quality of life of HIV-infected subjects. Patient Prefer Adherence. 2010;4:115-125.

27. D’Arminio Monforte A, Lepri AC, Rezza G, et al; I.CO.N.A. Study Group. Italian Cohort of Antiretroviral-Naïve Patients. Insights into the reasons for discontinuation of the first highly active antiretroviral therapy (HAART) regimen in a cohort of antiretroviral naïve patients. AIDS. 2000;14:499-507.
28. Paterson DL, Swindells S, Mohr J, et al. Adherence to protease inhibitor therapy and outcomes in patients with HIV infection. Ann Intern Med. 2000;133:21-30.

29. Bangsberg DR, Perry S, Charlebois ED, et al. Non-adherence to highly active antiretroviral therapy predicts progression to AIDS. AIDS. 2001;15:1181-1183.

30. Lima VD, Harrigan R, Bangsberg DR, et al. The combined effect of modern highly active antiretroviral therapy regimens and adherence on mortality over time. J Acquir Immune Defic Syndr. 2009;50:529-536.

31. Antinori A, Cozzi-Lepri A, Ammassari A, et al. Relative prognostic value of self-reported adherence and plasma NNRTI/PI concentrations to predict virological rebound in patients initially responding to HAART. Antivir Ther. 2004;9:291-296.

32. Colombo GL, Gaeta GB, Viganò M, et al. A cost-effectiveness analysis of different therapies in patients with chronic hepatitis B in Italy. Clinicoecon Outcomes Res. 2011;3:37-46.

33. Johnson LF, White PJ. A review of mathematical models of HIV/AIDS interventions and their implications for policy. Sex Transm Infect. 2011;87(7):629-634.
Therapeutics and Clinical Risk Management

\section{Publish your work in this journal}

Therapeutics and Clinical Risk Management is an international, peerreviewed journal of clinical therapeutics and risk management, focusing on concise rapid reporting of clinical studies in all therapeutic areas, outcomes, safety, and programs for the effective, safe, and sustained use of medicines. This journal is indexed on PubMed Central, CAS,

\section{Dovepress}

EMBase, Scopus and the Elsevier Bibliographic databases. The manuscript management system is completely online and includes a very quick and fair peer-review system, which is all easy to use. Visit http://www.dovepress.com/testimonials.php to read real quotes from published authors.

Submit your manuscript here: http://www.dovepress.com/therapeutics-and-clinical-risk-management-journal 